\title{
The Architecture of Transaction Networks: A Comparative Analysis of Hierarchy in Two Sectors
}

\section{Citation}

Luo, Jianxi, Carliss Y. Baldwin, Daniel E. Whitney, and Christopher L. Magee. "The Architecture of Transaction Networks: A Comparative Analysis of Hierarchy in Two Sectors." Industrial and Corporate Change 21, no. 6 (2012): 1307-1335.

\section{Published Version}

http://icc.oxfordjournals.org/content/21/6/1307.abstract

\section{Permanent link}

http://nrs.harvard.edu/urn-3:HUL.InstRepos:10687501

\section{Terms of Use}

This article was downloaded from Harvard University's DASH repository, and is made available under the terms and conditions applicable to Open Access Policy Articles, as set forth at http:// nrs.harvard.edu/urn-3:HUL.InstRepos:dash.current.terms-of-use\#OAP

\section{Share Your Story}

The Harvard community has made this article openly available.

Please share how this access benefits you. Submit a story.

\section{Accessibility}




\title{
The Architecture of Transaction Networks: A Comparative Analysis of Hierarchy in Two Sectors
}

\author{
Jianxi Luo* \\ Massachusetts Institute of Technology \\ luo@mit.edu \\ Carliss Y. Baldwin \\ Harvard Business School \\ cbaldwin@hbs.edu \\ Daniel E. Whitney \\ Massachusetts Institute of Technology \\ dwhitney@mit.edu \\ Christopher L. Magee \\ Massachusetts Institute of Technology \\ cmagee@mit.edu \\ * Corresponding author
}

January 30, 2012 


\title{
The Architecture of Transaction Networks: A Comparative Analysis of Hierarchy in Two Sectors
}

\begin{abstract}
Many products are manufactured in networks of firms linked by transactions, but comparatively little is known about how or why such transaction networks differ. This paper investigates the transaction networks of two large sectors in Japan at a single point in time. In characterizing these networks, our primary measure is "hierarchy," defined as the degree to which transactions flow in one direction, from "upstream" to "downstream." Our empirical results show that the electronics sector exhibits a much lower degree of hierarchy than the automotive sector because of the presence of numerous inter-firm transaction cycles. These cycles, in turn, reveal that a significant group of firms have two-way "vertically permeable boundaries": (1) they participate in multiple stages of an industry's value chain, hence are vertically integrated, but also (2) they allow both downstream units to purchase intermediate inputs from and upstream units to sell intermediate goods to other sector firms. We demonstrate that the 10 largest electronics firms had two-way vertically permeable boundaries while almost no firms in the automotive sector had adopted that practice.
\end{abstract}

Keywords: transactions; networks; vertical integration; hierarchy; industry architecture; innovation. 


\section{Introduction}

Transactions are the most basic form of inter-firm relationship and are a fundamental unit of economic analysis (Commons, 1934; Williamson, 1975; 1985). Inspired by the seminal work of Coase (1937) and Williamson (1975; 1985), a great deal of scholarly work has sought over the last three decades to explain transactions and the boundaries of firms. Until recently, however, the literature in both management and economics has focused on dyadic relationships between upstream sellers and downstream buyers.

But many products today are produced in networks spanning many firms (Powell, 1990; Langlois and Robertson, 1992; Sturgeon, 2002). Thus a growing body of research has been conducted at the level of an industry sector, in which "sector" is defined as a group of firms that collectively design and produce a coherent set of system products (Malerba, 2002). (Sectors have also been called "value networks," "modular production networks," and, more recently, “ecosystems.") Theorists, in turn, have suggested that sectors have "architectures," defined as the "rules and roles" that guide participants' expectations and the resulting division of labor across firms (Jacobides et al., 2006). When a new sector emerges, a range of architectures may be viable. But soon after, product definitions will be established; transactions will become standardized; and the sector's architecture will assume a stable form.

Sector architectures are known to vary over time and across product types, but comparatively little is known about how and why they differ. This paper aims to extend the empirical and theoretical work on sector architectures by investigating the transaction networks of two large sectors in Japan at a single point in time. In characterizing these networks, our primary measure is "hierarchy," defined as the degree to which transactions in the network flow in one direction, from "upstream" to "downstream." Our empirical results show that the electronics sector exhibits a much lower degree of hierarchy than the automotive sector because it contains numerous inter-firm transaction cycles.

We also show that the absence of hierarchy in a transaction network can reveal a key fact about firm behavior: the presence of a significant group of firms that have two-way "vertically permeable boundaries" (Jacobides and Billinger, 2006). Such firms exhibit two characteristics: (1) they participate in multiple stages of industry value chains and hence are vertically integrated, but also (2) they purchase inputs from and sell products to other firms in the sector. 
We demonstrate that the largest electronics firms had two-way vertically permeable boundaries while almost no firms in the automotive sector had adopted that practice.

This paper contributes to the emerging literature on industry architecture in several ways. We believe we are the first to conduct a formal cross-sector comparative analysis of transaction networks. Furthermore, to implement our analysis, we used a measure of hierarchy that can be applied to any transaction network. We are also among the first to link differences in architecture at the sector level to specific practices by firms within that sector. Our work thus shows how the strategies and decisions of firms at the micro-level give rise to observable architectural differences between sectors at the macro-level.

The remainder of this paper is organized as follows. Section 2 reviews the relevant literature. Section 3 describes how we measure the hierarchy of a network. Section 4 presents our data and empirical results. Section 5 explains how boundary choices by the largest firms in each sector give rise to different network patterns at the sector level. Section 6 discusses our results. Lastly, section 7 concludes by describing this paper's contributions, limitations, and future research directions.

\section{Literature Review}

Prior research on transactions has focused on the boundaries of the firm and related strategies, such as "make or buy" or vertical integration versus specialization. Because the literature in this area is vast, we are not able to do it justice here. (See Lafontaine and Slade, 2007 for a useful survey.) Instead we provide a selective review divided into three parts: (1) firm-level studies, (2) sector-level studies, and (3) transaction-network studies.

\section{Firm-Level Studies}

Most empirical studies of transactions at the firm level investigate the make-or-buy decisions of a single firm or the bilateral relationships between customers and suppliers in a particular industry. It has been shown that firms are more likely to outsource components when their assets are not co-specialized, when the component interfaces are standardized, and when high-powered incentives or property rights improve performance (Lafontaine and Slade, 2007). In particular, component modularity coupled with high rates of component innovation may 
motivate firms to specialize in particular segments of the value chain and can lead to vertical disintegration (Baldwin and Clark, 2000; Jacobides, 2005).

However, firms that bring together diverse knowledge bases may enjoy a competitive advantage in designing and producing complex system-level products (Brusoni and Prencipe, 2001). Thus Davies (2004) and Ceci and Masini (2011) found that large IT firms maintain a broad spectrum of capabilities along the value chain in order to offer integrated solutions to their customers. Furthermore, if the locus of technological innovation alternates between components and systems (Fine, 1998; Christensen, et al., 2002), vertically integrated firms may survive and prosper in the long run, even if they suffer during periods of intense component-level innovation (Helfat and Campo-Rembado, 2010). Empirically, Strojwas (2005) and Kapoor (2011) have shown that, in the U.S. semiconductor industry, both vertically integrated and specialized firms obtain adequate returns on capital over the business cycle. Empirical evidence from Japan also suggests that, despite high levels of component modularity and innovation, the largest Japanese electronics firms have remained vertically integrated, maintaining both systems and component divisions within their corporate boundaries (Luo, 2010, pp.114-5).

Firm-level studies also demonstrate that "make or buy" is not a clean dichotomy. In addition to purchasing components via arms-length transactions and making them in-house, firms frequently enter long-term relational contracts with their suppliers (Sako, 1992; Gulati 1995). Furthermore, many firms practice "concurrent sourcing," or "tapered integration"; that is, they both purchase a given component from external suppliers and make it in-house (Harrigan, 1985; Parmigiani, 2007; Parmigiani and Mitchell, 2009). Firms also practice "concurrent selling," in which upstream divisions both supply components to downstream divisions and sell them to external customers. For example, Jacobides and Billinger (2006) describe a clothing manufacturer that changed its strategy to allow upstream units to sell and downstream units to buy intermediate goods from other firms in its sector. The company thus went from being purely vertically integrated to having so-called "vertically permeable boundaries." Below we will show that this practice at the firm level can affect the architecture of transaction networks at the sector level.

\section{Sector-Level Studies}

Another set of studies looks at networks of firms whose relationships and boundaries 
co-evolve over time (Powell, 1990; Langlois and Robertson, 1992). In that literature, such groupings are variously called "sectors," "value networks," "modular production networks," and, recently, “ecosystems” (Malerba, 2002; Jacobides et al. 2006; Christensen and Rosenbloom, 1995; Sturgeon, 2002; Iansiti and Levien, 2004; Adner and Kapoor, 2010). To avoid confusion, this paper will consistently use the term "sector." An example is the automobile sector, which includes firms making finished products (that is, entire vehicles) in addition to those making sub-systems such as engines or interiors, components such as pistons or seats, and materials such as glass, plastic, and steel.

Within a sector, transactions in intermediate markets serve to link and coordinate complementary activities across firms (Jacobides and Winter, 2005; Dalziel, 2007; Baldwin, 2008; Adner and Kapoor, 2010). A number of studies at the sector level have explored how the internal boundaries of industries change and how intermediate markets emerge or disappear (Baldwin and Clark, 2000; Jacobides, 2005; Fixson and Park, 2008). Drawing on the engineering and product design literatures, Jacobides et al. (2006) defined "industry architecture" as a somewhat stable but evolving set of relationships that organize production and innovation processes in a sector. These relationships set the patterns by which labor and assets are divided among different types of firms, and the associated set of "rules and roles" that guide firms" behavior in the short and intermediate term. Sector architectures vary because different knowledge bases and evolutionary pathways lead to different specific constraints and opportunities (Nelson and Winter, 1982; Pavitt, 1984; Patel and Pavitt, 1997; Dosi, 1988; Malerba and Orsenigo, 1993, 1996, 1997; Cacciatori and Jacobides, 2005; Castellacci, 2007).

The application of formal network methods to the analysis of sectors offers a new challenge and opportunity for scholars. This has resulted in a growing body of literature aimed at understanding inter-firm networks in general and their effects on firm performance (Gulati, 1995, 1998; Sorenson and Stuart, 2001; Rosenkopf and Schilling, 2007; Schilling and Phelps, 2007). Of particular note is a recent comparative study by Rosenkopf and Schilling (2007) of the alliance networks in 32 industries in the United States. Interestingly, data on alliances and other knowledge-sharing ties (e.g., patent citations and career paths) are often accessible to scholars, while data on transactions are usually closely guarded by firms. Consequently, most sector-level network studies have looked at networks that transfer knowledge between firms rather than those that transfer goods via transactions. 
Transaction network analysis provides a different lens through which to view industry architectures and perform cross-sector comparisons. In the field of economic sociology, transaction networks have recently become the focus of theory, data collection, and quantitative analysis, but this emerging research stream has not been linked directly to the industry architecture literature. We address this gap in the next subsection.

\section{Transaction-Network Studies and the Concept of Hierarchy}

Scholars in economic sociology have studied transaction networks in "production markets," which are defined as markets for manufactured or processed goods (H. White, 2002a). According to Harrison White (2002b: 87), production markets show "persistent directionality in continuing flows of intermediate goods," in which "only a niche within an industry establishes you in a line of business."

Formally, a hierarchy is a structure in which entities such as firms are ordered or ranked with respect to a specific relationship (Ahl and Allen, 1996). Under this definition, networks in which firms are strictly ordered with respect to transactions (A sells to B, which sells to C, etc.) are hierarchies. Following the lead of H. White (2002a, b), Nakano and D. White (2007) studied the transaction network of firms in the Tokyo industrial district and showed that it exhibits strict hierarchy. They hypothesized that hierarchy is a general property of production markets because firms tend to become entrenched in their co-specialized positions and their roles as buyers and sellers. If each firm in a sector is purely focused on a single stage of the value chain, then transaction flows will mirror the flow of goods through the stages of production and the resulting transaction network will be hierarchical. Their hypothesis, however, was based on the analysis of a single network.

To summarize, firm-level studies suggest that transactions take many different forms and include complex practices such as relational contracts, concurrent sourcing (or tapered integration), and two-way vertically permeable boundaries. Sector-level studies, in turn, focus on networks of related firms and describe stable and recurring patterns in the flows of goods and knowledge within a sector. Formal network methods have been used to study flows of knowledge but, because of data limitations, transactions and flows of goods have not received as much attention. Finally, economic sociologists have begun to investigate transaction networks 
and have suggested that "persistent directionality" or "hierarchy" might be a property of networks that produce tangible goods. But at this point in time, they have not yet undertaken cross-sector comparisons.

This paper builds on and extends the prior literature in several ways. First, to enable cross-sector comparisons, we propose a formal way to measure hierarchy that can be applied to any transaction network. Then, building on previous sector-level studies, we analyze the transaction networks of two industry sectors at one point in time and show that their hierarchical network architectures differ significantly. That finding is then traced back to differences in the practices of the largest firms in each sector. To begin our analysis, we describe our measure of hierarchy.

\section{Measuring Hierarchy in the Architecture of Transaction Networks}

Although there is reason to suspect that hierarchy may vary across sectors, it has been difficult to detect and justify "how hierarchical" a network is, or to determine whether one network is "more hierarchical" than another. Recently, Luo and Magee (2011) have developed an approach for quantifying hierarchy in general networks. Their measure makes it possible to quantify hierarchical degree and thus objectively compare the architecture of transaction networks in different sectors. In the following, we briefly outline the method and provide an intuitive understanding of it.

At the most general level, transaction networks can be represented as directed graphs in which the nodes are firms and the links are transactions. Within a network, hierarchy is a generic structure in which the nodes are ordered with respect to their linkages. Flow hierarchy ${ }^{1}$ in a transaction network arises when there is a directional order of transactions from firm to firm through a series of stages (from "upstream" to "downstream"). In other words, if A sells to B, which sells to $\mathrm{C}$, then $\mathrm{A}, \mathrm{B}$, and $\mathrm{C}$ form a hierarchy with respect to those transactions.

But it is also possible for transaction networks to have cycles, in which A sells to B, which sells to A, either directly or indirectly. Cycles violate the principle of hierarchy because flows come back to their origin. Building on this fact, Luo and Magee (2011) have proposed to

\footnotetext{
1 Flow hierarchy is distinguished from other types of hierarchy, such as organizational hierarchy, status hierarchy, or nested hierarchy (Simon, 1962; Ahl and Allen, 1996).
} 
measure the degree of hierarchy in a network by capturing the extent to which it contains cycles. Their hierarchy metric $(h)$ is calculated as the percentage of links that are not included in any cycle:

$$
h=\frac{\sum_{i=1}^{m} e_{i}}{m}
$$

where $m$ is the number of links in the network and $e_{i}=0$ if link $i$ is in a cycle and 1 otherwise., ${ }^{2,3}$ In general, this metric categorizes transaction networks into three canonical architectures:

(1) Purely hierarchical (single-directional transaction flow), $h=1$;

(2) Purely cyclic (every transaction is part of a cycle), $h=0$; and

(3) Partially hierarchical (sequence and cycle are combined), $0<h<1$.

In the next section, we use this metric to compare the transaction networks of two industrial sectors in Japan.

\section{Data and Empirical Results}

In this section we apply the hierarchy metric and existing network visualization tools to the transaction data from the Japanese automotive and electronics sectors. We conduct a cross-sector comparative analysis and examine whether hierarchy varies between the sectors. Based on this analysis, we are able to reject the hypothesis that hierarchy is a general property of production markets (Nakano and D. White, 2007).

\subsection{Data}

We extracted supplier-customer transactional relationship data from the series data books "The Structure of the Japanese Auto Part Industry" and "The Structure of the Japanese

\footnotetext{
${ }^{2}$ In some applications, it is useful to weight the links by, for example, the volume of flows. However, in this paper we focus on unweighted networks because our empirical data do not include complete information about the weights of all the links. In addition, this metric only counts whether a link is involved in any cycle but does not take into account the lengths of cycles. Completely tracing cycle sizes is computationally difficult when networks are large and adds little insight.

3 This metric is advantageous in its clarity and ease of computation in comparison to other potential metrics. It has wide applicability in other network systems, such as organizations, teams, and products. For details on this metric, including the algorithm to calculate it for large-scale networks, see Luo (2010, chapters 2 and 3) and Luo and Magee (2011).
} 
Electronics Industry," which are based on regular surveys by Dodwell Marketing Consultants. The company directories in these two data books provide information on the major customers and suppliers for each firm. Such information allowed us to extract "who-supplies-whom" connections between firms, ${ }^{4}$ which then enabled us to build the transaction networks for those two sectors. The data books were available only in hard copy and had to be manually entered into an electronic database. For the automotive sector, we had access to data books published in 1983, 1993, and 2001; for the electronics sector, we unfortunately had access to just one data book published in 1993. ${ }^{5}$ Thus our cross-sector comparison focuses on 1993. (Even though our comparative analysis focuses on just 1993, we present two other years of data from the automotive sector as a stability check to show that fundamental patterns were stable in that sector over an 18-year period. Unfortunately, a similar stability check was not possible for the electronics industry. We discuss this limitation in the conclusion.)

The two sectors are similar on some dimensions but not on others. Both manufacture complex physical products; hence they qualify as "production markets" under H. White's (2002a) definition. Both are located within the same national and cultural setting but differ substantially in terms of their key technologies and knowledge bases. Table 1 lists the largest 10 firms by revenue in 1993 for the two sectors and also reports the numbers of suppliers and customers for each firm. Overall, the largest firms in each sector also had the largest number of suppliers. (The overlap between the largest 10 firms by revenue and by number of suppliers was $100 \%$ in the automotive sector and $90 \%$-- a one-firm discrepancy -- in the electronics sector.) With respect to customers, there was a notable difference between the two sectors. In the automotive sector, the largest firms had no customers within the sector, while some of the largest electronics firms (Matsushita Electric, Toshiba, NEC, Hitachi, and Fujitsu) also had the highest numbers of customers. (These differences will be analyzed in greater detail in section 5.1.)

\footnotetext{
4 We do not have details on the specifics of individual transactions.

5 We believe the data actually represent the situation approximately two to three years before the publishing year, because the publications were refreshed every two to three years.
} 
Table 1 The largest 10 firms in the automotive and electronics sectors in Japan in 1993

\begin{tabular}{|c|c|c|c|c|c|}
\hline & Largest 10 Firms & Year Ending & $\begin{array}{c}\text { Revenue } \\
\text { (Billion Yen) }\end{array}$ & $\begin{array}{l}\text { Number of } \\
\text { Suppliers }\end{array}$ & $\begin{array}{c}\text { Number of } \\
\text { Customers } * *\end{array}$ \\
\hline \multirow{10}{*}{ 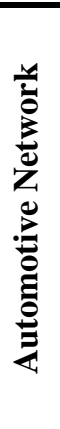 } & Toyota Motor & June 1993 & 9,031 & 166 & $\overline{0}$ \\
\hline & Nissan Motor & March 1993 & 3,897 & 176 & 0 \\
\hline & Honda Motor & March 1993 & 2,695 & 169 & 0 \\
\hline & Mitsubishi Motors & March 1993 & 2,615 & 226 & 0 \\
\hline & Mazda Motor & March 1993 & 2,191 & 157 & 0 \\
\hline & Isuzu Motors & October 1993 & 1,199 & 135 & 0 \\
\hline & Suzuki Motor & March 1993 & 1,053 & 125 & 0 \\
\hline & Fuji Heavy Industries & March 1993 & 873 & 127 & 0 \\
\hline & Daihatsu Motor & March 1993 & 785 & 99 & 0 \\
\hline & Hino Motors & March 1993 & 632 & 98 & 0 \\
\hline \multirow{10}{*}{ 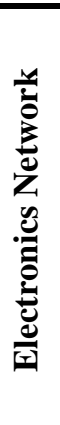 } & Hitachi & March 1992 & 7,766 & 52 & 17 \\
\hline & Matsushita Electric Industrial* & March 1992 & 7,450 & 30 & 27 \\
\hline & Toshiba & March 1992 & 4,722 & 40 & 26 \\
\hline & Sony & March 1992 & 3,915 & 36 & 3 \\
\hline & NEC & March 1992 & 3,744 & 38 & 18 \\
\hline & Fujitsu & March 1992 & 3,422 & 34 & 12 \\
\hline & Mitsubishi Electric & March 1992 & 3,343 & 33 & 7 \\
\hline & Canon & December 1991 & 1,869 & 9 & 2 \\
\hline & Sanyo Electric & November 1991 & 1,616 & 15 & 3 \\
\hline & Sharp & March 1992 & 1,555 & 23 & 3 \\
\hline
\end{tabular}

* Matsushita Electric Industrial was renamed to Panasonic Corporation in 2008.

** "Customers" are within the sector and do not include end-users.

For each sector in a specific year, we constructed a directed network in which nodes are firms and links are supplier-customer transactional relationships. The transactions indicated are compensated transactions of physical products and not services or intellectual property. Table 2 contains basic network statistics, including number of firms $(n)$, number of transactional relationships $(m)$, and average degree ${ }^{6}(k=m / n)$. The automotive transaction networks have more nodes, more links, and a higher average degree than the electronics transaction network.

\footnotetext{
${ }^{6}$ In graph theory, the degree of a node means the number of nodes connected to it. In a directed network, there are two types of degrees applying to a single node: in-degree (number of nodes connected to it) and out-degree (number of nodes it connects to). The average in-degree and out-degree of a network are equal.
} 
Table 2 Network descriptive statistics

\begin{tabular}{l|cccc}
\hline \multicolumn{1}{c|}{ Network Attributes } & Japanese Automotive Sector & $\begin{array}{c}\text { Japanese } \\
\text { Electronics } \\
\text { Sector }\end{array}$ \\
\hline Year & 1983 & 1993 & 2001 & 1993 \\
Number of Firms $(n)$ & 356 & 679 & 627 & 227 \\
$\begin{array}{l}\text { Number of Transactional } \\
\text { Relationships }(m)\end{array}$ & 1480 & 2437 & 2175 & 648 \\
Average Degree $(k=m / n)$ & 4.157 & 3.589 & 3.469 & 2.855 \\
\hline
\end{tabular}

With these basic statistics in hand, we now analyze each sector's transaction network using standard network tools in addition to our hierarchy metric. In the subsections that follow, we present graphical visualizations, matrix visualizations, hierarchy metric calculations, and an analysis of embedded cycles for the two networks.

\subsection{Graphical Visualization}

We used Netdraw, a leading social-network visualization program (Borgatti, 2002), to create graphical images of the transaction networks in the automotive and electronics sectors in 1993. The visualizations (Figure 1) allow us to see that the automotive network has more nodes and links and that both networks contain a number of "hubs" (nodes with many links). Both networks are also densely connected, displaying what Rosenkopf and Schilling (2007) call a "spiderweb" structure. Although informative, such diagrams are not designed to reveal the presence of hierarchy or cycles. 


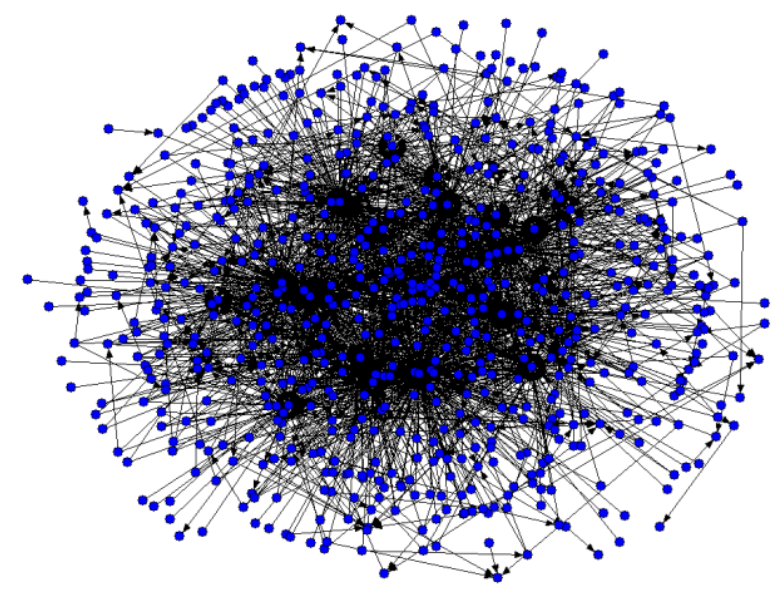

A) Automotive Sector

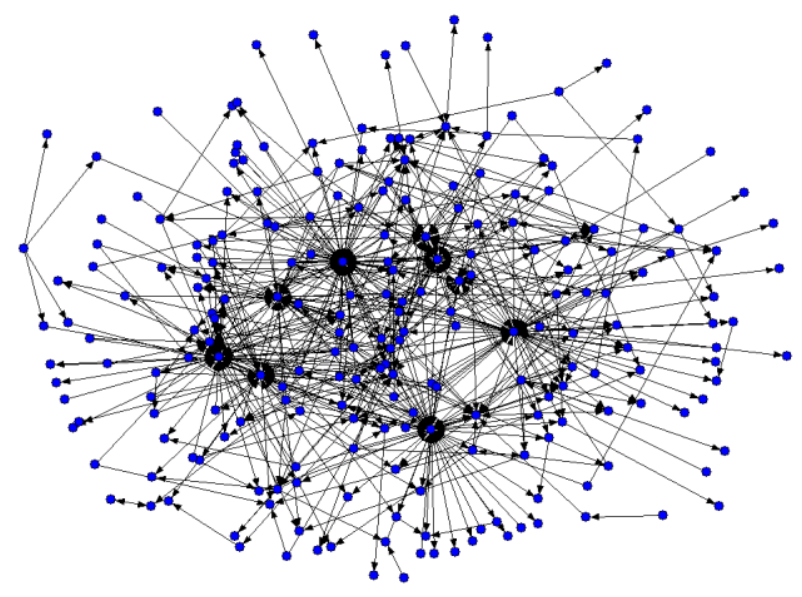

B) Electronics Sector

Figure 1 Japanese interfirm transaction networks in 1993

\subsection{Matrix Visualization}

Matrices are better than graphs at revealing flow hierarchies in networks. In engineering, a square Design Structure Matrix (DSM) is often used to examine the dependencies between design elements or communication linkages between designers (Eppinger et al., 1994; Sosa et al., 2004; MacCormack et al., 2006). Generalizing these procedures, we used a square DSM to examine the pattern of linkages between firms in the two transaction networks. Figure 2 shows the results. The elements on both axes are firms listed in the same order, and the dots represent transactions. If firm $j$ is a customer of firm $i$, we put a dot in the cell $(i, j)$ of the matrix. In the automotive DSM, for example, dot $(359,524)$ indicates that Nippon Denso (firm 524) is a customer of Arai Seisakusho (firm 359). In the electronics DSM, dot $(147,124)$ indicates that Omron (firm 124) is a customer of Matsushita Electric Industrial (firm 147, since renamed Panasonic). 


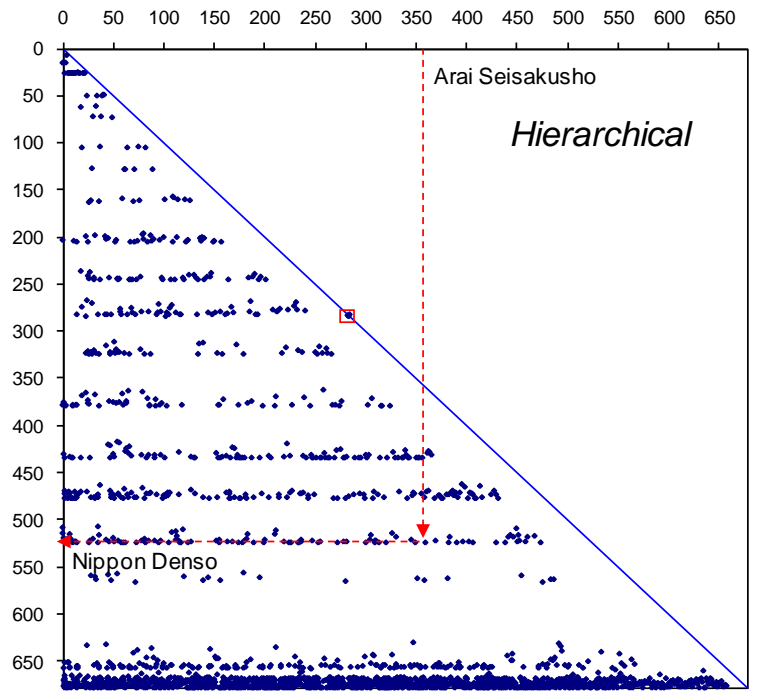

A) Automotive Sector

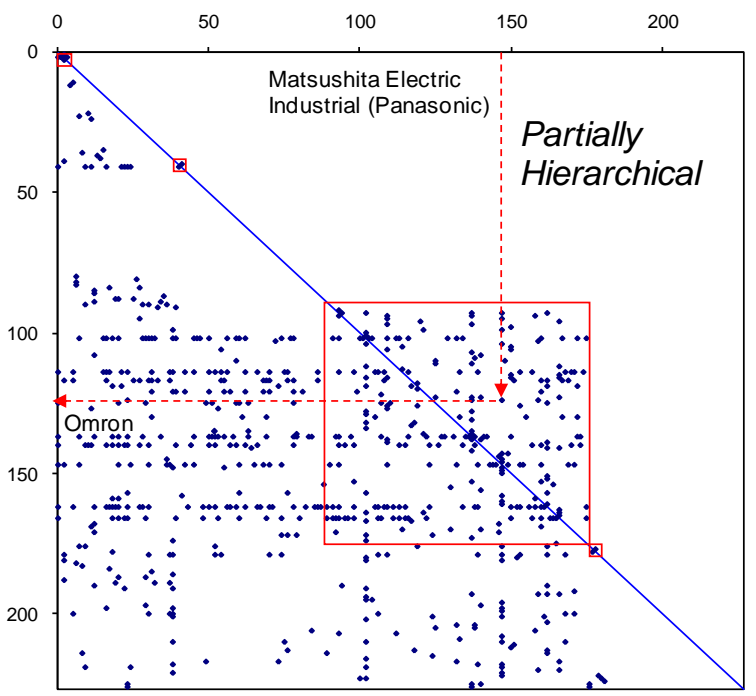

B) Electronics Sector

Figure 2 Dependency Structure Matrices for Japanese interfirm transaction networks in 1993.

The small boxes drawn inside the DSMs encapsulate strong components (Wassserman and Faust, 1994), in which all nodes are on cycles with each other. The automotive sector DSM shows there is only one strong component in the automotive network, and its size is ( 3 nodes, 3 links). In contrast, in the electronics network, there are four strong components, and their sizes are (84 nodes, 254 links), ( 3 nodes, 4 links), ( 2 nodes, 2 links), and ( 2 nodes, 2 links), respectively. The dots in a row indicate how many suppliers the firm in that row has. In DSM A, the dense bottom rows are the large car manufacturers like Toyota and Nissan. No such dominance appears in B.

In the DSMs in Figure 2, firms are ordered according to their "visibilities"; thus firms on connected cycles have been grouped together (MacCormack et al., 2010). In the automotive DSM, almost all dots are below the main diagonal, indicating that this network is extremely hierarchical. In contrast, the electronics DSM has many dots above the diagonal, indicating that many firms participate in transaction cycles. Furthermore, most of these cycles are intertwined together in one strongly connected "component" (Wasserman and Faust, 1994). That component, which appears as the large block near the center of Figure 2, encapsulates 84 firms $(37 \%$ of the total) and 254 links (39\% of the transactional relationships). All firms in this component participate in transaction cycles with each other, and thus the network is far from being purely hierarchical.

The comparison of the two DSMs in Figure 2 reveals significant qualitative differences in hierarchy in the two sectors. We now use the Luo and Magee (2011) metric, described earlier, to quantify the differences.

7 "Visibility" is the count of all the direct and indirect dependencies a node possesses with other nodes (MacCormack et al., 2006). 


\subsection{Hierarchy Measurement}

We computed the hierarchy metric, $h$, for the Japanese electronics transaction network in 1993 and the automotive transaction networks in 1983, 1993, and 2001. Table 3 shows the number of firms involved in cycles and the degree of hierarchy $(h)$ for each network. A comparison for 1993 shows that the electronics sector $(h=0.5957)$ is quantitatively much less hierarchical than the automotive sector $(h=0.9988)$ because of the presence of many transaction cycles. Furthermore, the degree of hierarchy in the automotive sector in Japan did not change much over time. (Unfortunately, we did not have corresponding data for the electronics sector.)

Table 3 Cycles and Hierarchy in Two Sectors

\begin{tabular}{|c|c|c|c|c|c|}
\hline \multirow[b]{2}{*}{ Network Attributes } & \multirow{2}{*}{\multicolumn{3}{|c|}{ Japanese Automotive Sector }} & \multicolumn{2}{|c|}{$\begin{array}{c}\text { Japanese Electronics } \\
\text { Sector }\end{array}$} \\
\hline & & & & $\begin{array}{l}\text { complete } \\
\text { network }\end{array}$ & $\begin{array}{l}10 \text { largest } \\
\text { firms } \\
\text { removed }\end{array}$ \\
\hline Year & 1983 & 1993 & 2001 & 1993 & 1993 \\
\hline Number of Firms in Cycles $\left(n_{\mathrm{c}}\right)$ & 4 & 3 & 2 & 91 & 13 \\
\hline Number of Links in Cycles $\left(m_{\mathrm{c}}\right)$ & 4 & 3 & 2 & 262 & 14 \\
\hline Degree of Hierarchy $\left(h=1-m_{\mathrm{c} /} / m\right)$ & 0.9973 & 0.9988 & 0.9991 & 0.5957 & 0.9367 \\
\hline Cycle Tracking & $\begin{array}{c}2 \text { two-node } \\
\text { cycles }\end{array}$ & $\begin{array}{l}1 \text { three-node } \\
\text { cycle }\end{array}$ & $\begin{array}{l}1 \text { two-node } \\
\text { cycle }\end{array}$ & many* & $\begin{array}{c}7 \text { two-node } \\
\text { cycles }\end{array}$ \\
\hline
\end{tabular}

* In the 1993 electronics sector network, there were 51 two-node cycles, 12 three-node cycles, 92 four-node cycles, 107 five-node cycles, 598 six-node cycles, and many larger cycles. There were four strong components in which all nodes are in cycles with each other. These four strong components are shown as boxes in the electronics sector DSM in Figure 5.

\subsection{Transaction Cycles}

The automotive transaction network is very hierarchical, and thus it is clear which firms are "upstream" and which are "downstream." In this sector, only one or two small cycles were found in the network in any year, and in all years the transactions involved in cycles were of only minor volume. ${ }^{8}$ Figure 3 shows the only cycle present in 1993. In the early 2000s, that cycle

${ }^{8}$ The Dodwell data for the auto part industry has some but incomplete information about the portion of procurement 
disappeared as Toyota Auto Body acquired the other two firms (Araco and Gifu Auto Body Industry).

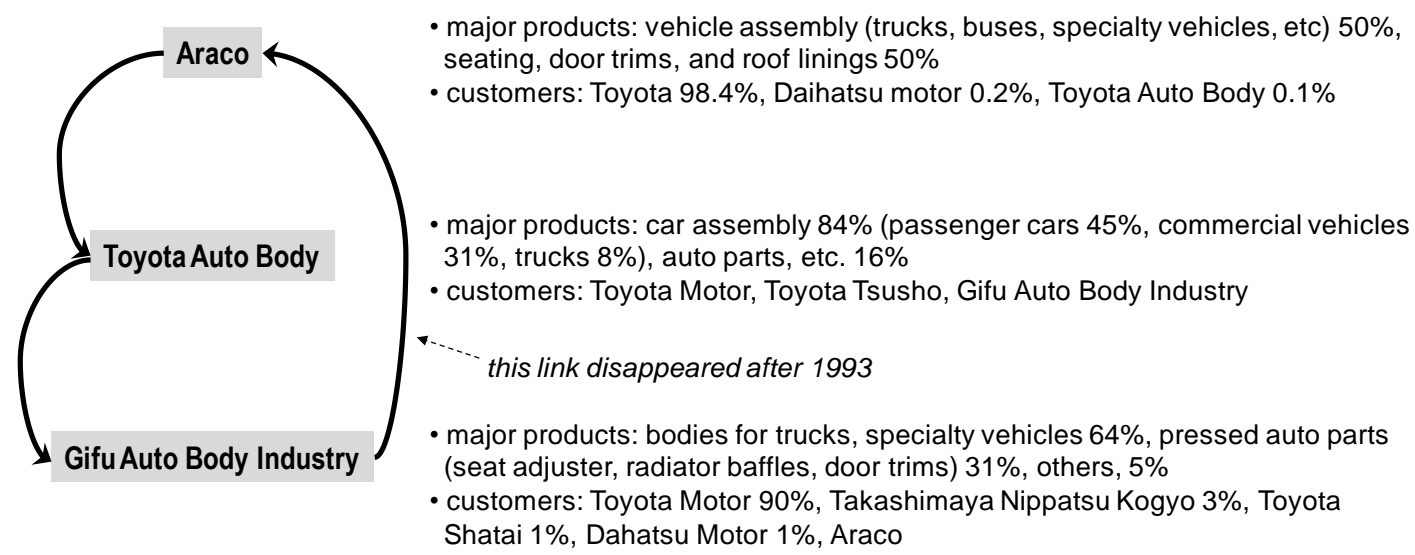

Toyota Auto Body Co Ltd (TA) acquired the vehicle manufacturing and sales business of Araco Corp (AR), a manufacturer of automotive seat cover, and a unit of Toyota Motor Corp (TM) - announced on October 1st, 2004 Toyota Auto Body Co Ltd (TA) acquired the remaining 89.09\% interest of Gifu Auto Body Co Ltd, a manufacturer of automobile and truck bodies - announced on October 1st, 2007

Figure 3 The only cycle in the automotive sector in 1993

In contrast, approximately $40 \%$ of the transactional relationships in the electronics sector in 1993 were involved in cycles, including 51 two-node cycles, 12 three-node cycles, and many larger cycles. Figure 4 presents two examples extracted from the data. In one case, Fujitsu purchased components and power units from Shindengen Electric Manufacturing for use in its personal computer, server, and system products, and then supplied computer, server, and system products to Shindengen Electric. In another case, Matsushita Electric Industrial (now Panasonic) sold components to Matsushita Electric Works, which sold materials for making electronic boards to CMK. CMK, in turn, was a supplier of printed circuit board (PCB) assemblies to Matsushita Electric Industrial. (As indicated in the caption, Matsushita Electric Industrial was a significant shareholder of Matsushita Electric Works, which was in turn a minor shareholder in CMK. Cross-holding of shares is a feature of the keiretsu system and is common among Japanese corporations (Aoki, 1988). In general, we treated firms as separate if the major shareholder owned less than $50 \%$ of outstanding shares. Note, however, that if we treat 
Matsushita Electric Industrial and Matsushita Electric Works as one firm, a cycle persists between Matsushita and CMK. We discuss the keiretsu system in relation to our findings in Section 6.)

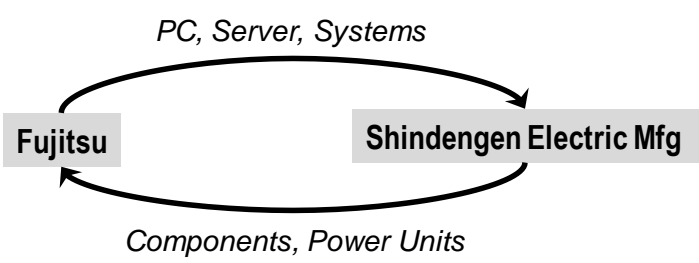

A) An example of 2-node cycle

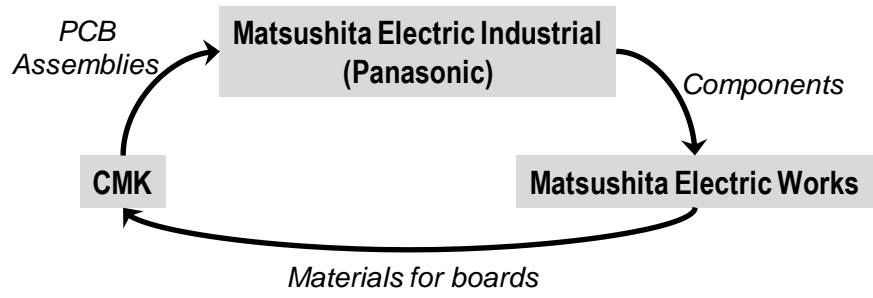

B) An example of 3-node cycle

Figure 4 Example cycles found in the electronics transaction network

Note: Fujitsu owned a 7.2\% share of Shindengen Electric Mfg in 1992. Matsushita Electric Industrial owned a 32.5\% share of Matsushita Electric Works, and Matsushita Electric Works owned a 3.6\% share of CMK in 1992. Information on what was transacted was described to one of the authors (Luo) by managers at Fujitsu and Panasonic, respectively, based on their knowledge of the firms' business in the early 1990s.

Thus the electronics transaction network is only partially hierarchical. Inside the strongly connected component of the network (the large central block in Figure 2B), it is not clear which firms are "upstream" and which are "downstream." Hence this network is a counterexample to Nakano and D. White's (2007) hypothesis that hierarchy is a general property of transaction networks in production markets.

\section{What Hierarchy and Cycles Reveal about the Practices of Firms}

The differences observed in the hierarchy of the two transaction networks help expand our knowledge of industry architecture and complement prior empirical studies in economic sociology. The value of this knowledge for management scholars, however, is limited unless facts about network architecture can be linked to the practices of firms in important ways. In this section, we ask the following question: What does the presence of hierarchy or cycles in a 
transaction network reveal about the practices of firms in that network?

In a purely hierarchical transaction network, firms occupy well-defined positions with respect to one another. Firm A is either upstream from Firm B (a direct or indirect supplier), downstream from Firm B (a direct or indirect customer), or unrelated (neither a supplier nor a customer). In contrast, in a non-hierarchical transaction network, some firms by definition participate in transaction cycles. And for transaction cycles to exist, some firms in the industry must have two-way vertically permeable boundaries. Such firms concurrently source and sell; that is, (1) they participate in multiple stages of industry value chains, but also (2) they both purchase inputs for downstream units from other firms in the sector (concurrent sourcing) and sell outputs from upstream units to other firms in the sector (concurrent selling). ${ }^{9}$

In Figure 5, for example, Firm $\mathrm{A}$ in the electronics sector makes substrates (a component), chipsets (a subsystem), and entire systems. ${ }^{10}$ Internally, its substrate unit transfers goods to the chipset unit, which in turn transfers goods to the systems unit. But the substrate unit also sells products to Firm B, a specialized chipset maker, while the systems unit purchases chipsets from that firm.
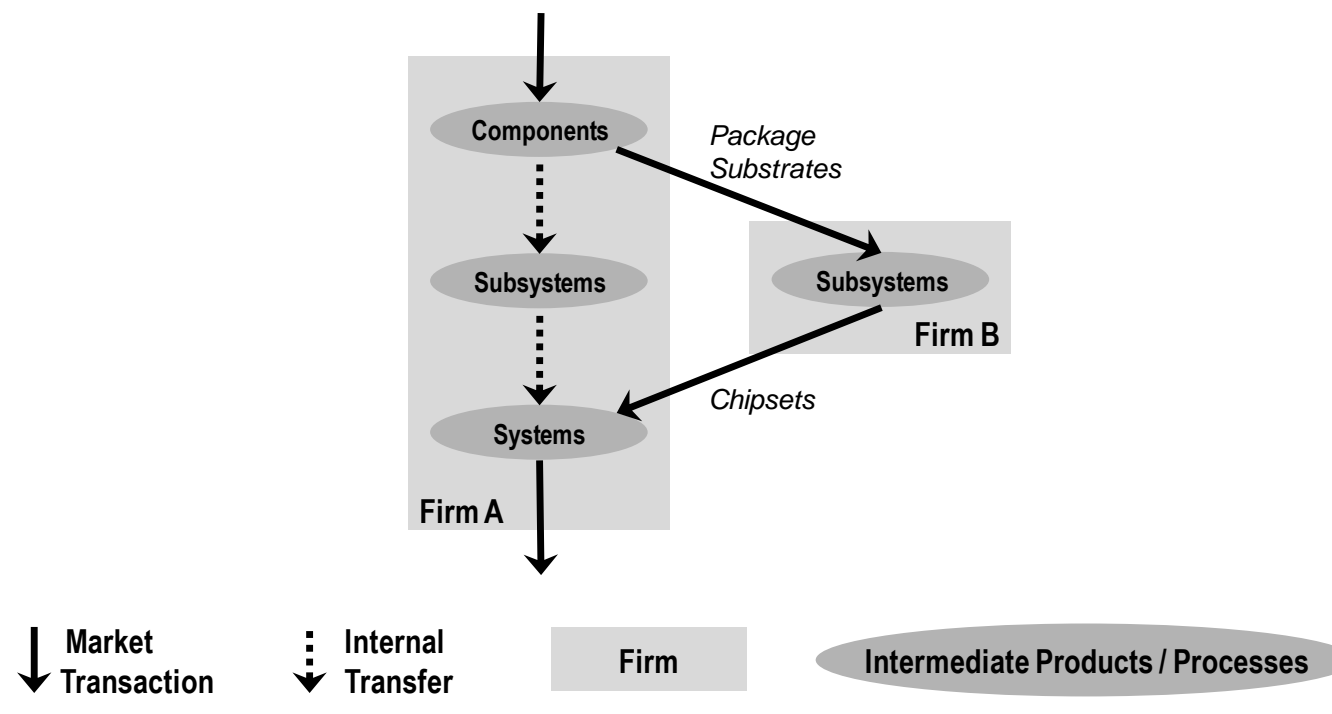

Figure 5 Vertically permeable boundary and interfirm transaction cycle.

9 Our definition of concurrent sourcing/selling considers all of the focal firm's transactional relations with other firms in the sector, hence is slightly broader than (although consistent with) the definition used in firm-level studies, which focus on individual components (see, for example, Parmigiani, 2007).

10 This is a real example, which was described to one of the authors (Luo) by an industry participant in 2009. 
Thus Firm A has two-way vertically permeable boundaries. It is vertically integrated in the sense that goods flow from division to division within the firm, but at the same time its downstream division buys inputs from external suppliers in the sector and its upstream division sells outputs to external customers in the sector. Note that although Firms A and B both participate in the same cycle, only Firm A, by our definition, has vertically permeable boundaries. Thus Firm A is critical to the cycle. If, for whatever reason, Firm A stopped outsourcing chipsets or selling substrates, the cycle would disappear. In other words, specialized firms (like Firm B) cannot instigate cycles unless a firm with broader scope (like Firm A) both sells to them and buys from them, either directly or indirectly. As such, a sector made up of only specialized firms like Firm B will be purely hierarchical.

Figure 6 shows another way in which two-way vertically permeable boundaries can give rise to transaction cycles. ${ }^{11}$ Here Firms C and D have internal divisions that participate in the upstream and downstream stages of different value chains within the same sector. For example, Firm C might make printed circuit boards (a subsystem) and television sets (a system), while Firm D makes flat panel displays (a subsystem) and computers (a system). In this hypothetical example, there are no product flows between the subsystem and system divisions within each firm, but both firms are present in different stages of technologically related value chains. Firm C sells printed circuit boards (PCBs) to Firm D and purchases flat panel displays from it, and thus a transaction cycle exists between the two firms. And both firms, by our definition, have two-way vertically permeable boundaries. ${ }^{12}$

\footnotetext{
11 This is a hypothetical example. Cycles like this are theoretically possible but they did not arise in our data from the 10 largest firms in the electronics sector. Whether they exist at all is an open empirical question, but we include this case for completeness.

12 Transaction cycles can also arise across sectors if some firms adopt a strategy of unrelated diversification. The incidence of cross-sector cycles depends on the prevalence of business groups made up of technologically unrelated divisional units. Investigating such patterns is an interesting topic for future research.
} 


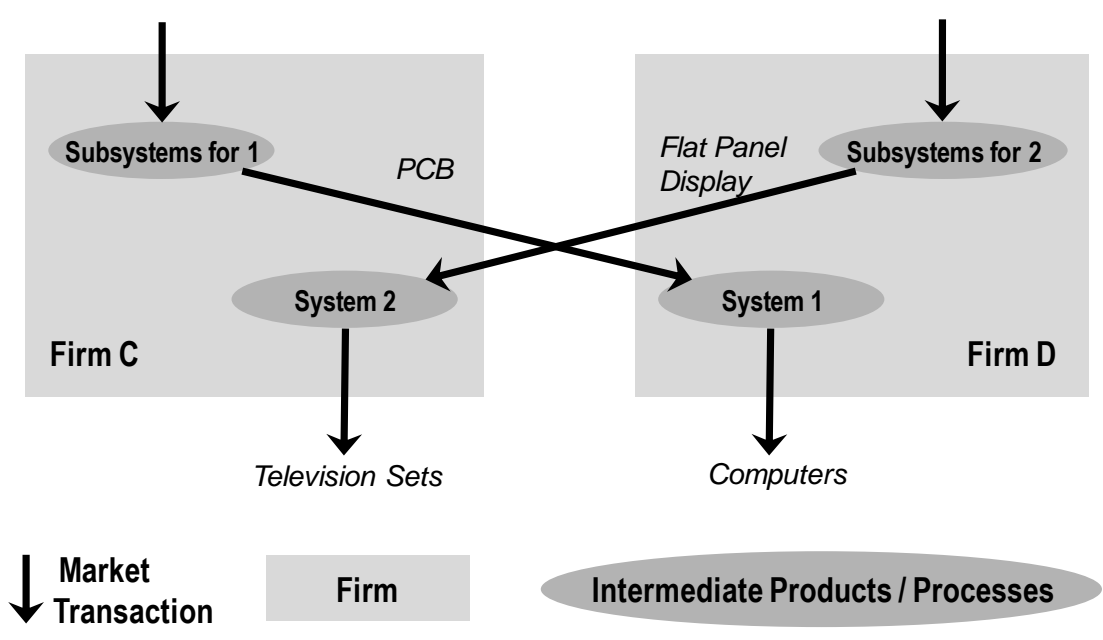

Figure 6 Vertically permeable boundaries and interfirm transaction cycle: a different example.

We formalize the relationship between transaction cycles and vertically permeable boundaries in the following way: Any inter-firm transaction cycle must include at least one firm that concurrently sources and sells, hence whose vertical boundaries are permeable in both directions. Therefore, an observable aspect of a transaction network's structure, specifically the presence or absence of cycles, can reveal a key fact about firms in the sector, i.e., whether a subset of firms has two-way vertically permeable boundaries. Finally, it is important to recognize that a small number of firms with two-way vertically permeable boundaries can involve many other firms in transaction cycles.

Returning to the empirical results in section 4, we can now assert that some firms in the electronics sector have two-way vertically permeable boundaries. But the question becomes, which firms?

\subsection{The Largest Firms}

On further examination, we found that most of the two- and three-firm cycles in the electronics sector included at least one of the 10 largest firms (see Table 1). Thus we hypothesized that the largest firms play a critical role in forming cycles in this sector. We tested this hypothesis by removing these firms from the sector's transaction network. The results are shown in the last column of Table 3. In the new network without the largest firms, only 13 of the other firms participated in cycles (down from 91), while just 14 out of 221 links were in cycles (resulting in $h=0.9367$ ). Thus a relatively small group of firms (the 10 largest) played a major 
role in determining the architecture of this transaction network.

Pursuing this observation, we further compared the two sectors with regard to the largest firms' network positions and links with each other. First, we found that the largest firms were located differently in their respective transaction networks. As shown in Table 1, the largest automotive firms (such as Toyota, Nissan, Honda, and Mitsubishi) had no customers within the sector although they had many suppliers. Essentially, they were final assemblers and systems integrators located in the most downstream positions of the value chain. They might have concurrently sourced components from both internal units and external suppliers, ${ }^{13}$ but they did not sell intermediate goods to other firms in their sector - at least not in significant volumes. (Our data books list only the "major" customers and suppliers of a firm; thus small transactions may have been omitted.)

In contrast, in the electronics sector, some of the largest firms (such as Matsushita Electric, Toshiba, NEC, Hitachi, and Fujitsu) had the highest numbers of customers and the highest numbers of suppliers. These firms bought components from external suppliers for their system products, and they also sold products from their component divisions to other firms in the sector. Thus these firms were located in the middle of the (partial) hierarchy of the electronics transaction network. Indeed, all but one (Canon) was located in the strongly connected component (see Figure 2B).

Thus nine of the 10 largest electronics firms were reciprocally linked by transactions. One further question then arises: Did those firms buy and sell directly or indirectly? When we investigated this question, we found only one direct link between the nine firms: from Hitachi to Sharp. In other words, the largest electronics firms did not transact directly with each other; instead, they were cyclically connected through chains of transactions. The absence of direct transactions suggests that other cycle participants (either customers or suppliers) played intermediary roles within the architecture of this sector.

Finally, when we further traced the transactional relationships of the largest firms, we found evidence of significant network sharing in both sectors. For example, 97\% of Toyota's direct suppliers also sold (either directly or indirectly) to at least one other large firm in the sector. In other words, only 3\% (5 out of 166 firms) dealt exclusively with Toyota. ${ }^{14}$ The same

${ }_{13}$ Concurrent sourcing is a common practice of automotive manufacturers (Fine and Whitney, 1999).

${ }^{14}$ As of March 1993, a 15.8\% stake of Daihatsu and 11.2\% stake of Hino were held by Toyota. Daihatsu and Hino 
pattern was observed for the other nine largest firms (see Table 4).

Table 4 Supplier Sharing in the Automotive Sector

\begin{tabular}{l|cccc}
\hline $\begin{array}{c}\text { Largest firms by } \\
\text { revenue }\end{array}$ & $\begin{array}{c}\text { Number of } \\
\text { direct } \\
\text { suppliers }\end{array}$ & $\begin{array}{c}\text { Portion of direct } \\
\text { suppliers that also } \\
\text { directly supply to any } \\
\text { other of the largest 10 } \\
\text { firms }\end{array}$ & $\begin{array}{c}\text { Portion of direct } \\
\text { suppliers that } \\
\text { indirectly supply to } \\
\text { any other of the } \\
\text { largest 10 firms }\end{array}$ & $\begin{array}{c}\text { Sum: Direct plus } \\
\text { Indirect }\end{array}$ \\
\hline Toyota Motor & 166 & $86 \%$ & $11 \%$ & $97 \%$ \\
Nissan Motor & 176 & $86 \%$ & $10 \%$ & $96 \%$ \\
Mitsubishi Motor & 226 & $77 \%$ & $18 \%$ & $95 \%$ \\
Mazda Motor & 157 & $78 \%$ & $12 \%$ & $90 \%$ \\
Honda Motor & 169 & $75 \%$ & $97 \%$ & $92 \%$ \\
Suzuki Motor & 125 & $83 \%$ & $8 \%$ & $93 \%$ \\
Daihatsu Motor & 99 & $85 \%$ & $7 \%$ & $90 \%$ \\
Fuji Heavy Industries & 127 & $83 \%$ & $11 \%$ & $93 \%$ \\
Isuzu Motors & 135 & $82 \%$ & $13 \%$ & $92 \%$ \\
Hino Motors & 98 & $79 \%$ & $11 \%$ & $93 \%$ \\
\hline \multicolumn{1}{c}{ Average } & 147.8 & $82 \%$ & & $92 \%$ \\
\hline
\end{tabular}

There was also a high level of supplier sharing in the electronics sector (see Table 5). Fully $100 \%$ of the largest 10 firms' direct suppliers also sold (either directly or indirectly) to the other firms in the top 10. In other words, even though the top 10 firms did not transact with each other directly, their supply networks overlapped. Moreover, the same pattern was true for customers: For nine of the 10 largest firms, every customer had a direct or indirect relationship with at least one other firm in the top 10. (Again, the exception was Canon.)

were specialized in small/mini cars and trucks/buses respectively, and were considered member firms of the Toyota Group. We tested if grouping of them has a strong effect on the result by making Toyota, Daihatsu, and Hino into one node (Toyota group). "Toyota Group" had 246 direct suppliers, and 89\% of them directly or indirectly supplied at least one other large firm in the sector. This grouping did not change the results for other firms. 
Table 5 Supplier and Customer Sharing in the Electronics Sector

A) Supplier Sharing

\begin{tabular}{l|cccc}
\hline $\begin{array}{c}\text { Largest firms by } \\
\text { revenue }\end{array}$ & $\begin{array}{c}\text { Number of } \\
\text { direct } \\
\text { suppliers }\end{array}$ & $\begin{array}{c}\text { Portion of direct suppliers } \\
\text { that also directly supply } \\
\text { to any other of the largest } \\
10 \text { firms }\end{array}$ & $\begin{array}{c}\text { Portion of direct } \\
\text { suppliers that indirectly } \\
\text { supply to any other of } \\
\text { the largest 10 firms }\end{array}$ & $\begin{array}{c}\text { Sum: Direct plus } \\
\text { Indirect }\end{array}$ \\
\hline Hitachi & 52 & $79 \%$ & $21 \%$ & $100 \%$ \\
Matsushita & 30 & $73 \%$ & $27 \%$ & $100 \%$ \\
Toshiba & 40 & $75 \%$ & $25 \%$ & $100 \%$ \\
Sony & 36 & $89 \%$ & $11 \%$ & $100 \%$ \\
NEC & 38 & $61 \%$ & $39 \%$ & $100 \%$ \\
Fujitsu & 34 & $85 \%$ & $15 \%$ & $100 \%$ \\
Mitsubishi Electric & 9 & $91 \%$ & $10 \%$ & $100 \%$ \\
Canon & 15 & $87 \%$ & $13 \%$ & $100 \%$ \\
Sanyo Electric & 23 & $83 \%$ & $17 \%$ & $100 \%$ \\
Sharp & 31 & $81 \%$ & $19 \%$ & $100 \%$ \\
\hline \multicolumn{1}{c}{ Average } & & & & $10 \%$ \\
\hline
\end{tabular}

B) Customer Sharing

\begin{tabular}{|c|c|c|c|c|}
\hline $\begin{array}{l}\text { Largest firms by } \\
\text { revenue }\end{array}$ & $\begin{array}{c}\text { Number of } \\
\text { direct } \\
\text { customers }\end{array}$ & $\begin{array}{c}\text { Portion of direct } \\
\text { customers that also } \\
\text { directly purchase from } \\
\text { any other of the largest } 10 \\
\text { firms }\end{array}$ & $\begin{array}{l}\text { Portion of direct } \\
\text { customers that } \\
\text { indirectly purchase } \\
\text { from any other of the } \\
\text { largest } 10 \text { firms }\end{array}$ & $\begin{array}{l}\text { Sum: Direct } \\
\text { plus Indirect }\end{array}$ \\
\hline Hitachi & 17 & $47 \%$ & $53 \%$ & $100 \%$ \\
\hline Matsushita & 27 & $41 \%$ & $59 \%$ & $100 \%$ \\
\hline Toshiba & 26 & $46 \%$ & $54 \%$ & $100 \%$ \\
\hline Sony & 3 & $33 \%$ & $67 \%$ & $100 \%$ \\
\hline NEC & 18 & $44 \%$ & $56 \%$ & $100 \%$ \\
\hline Fujitsu & 12 & $50 \%$ & $50 \%$ & $100 \%$ \\
\hline Mitsubishi Electric & 7 & $57 \%$ & $43 \%$ & $100 \%$ \\
\hline Canon & 2 & $50 \%$ & $0 \%$ & $50 \%$ \\
\hline Sanyo Electric & 3 & $100 \%$ & $0 \%$ & $100 \%$ \\
\hline Sharp & 3 & $67 \%$ & $33 \%$ & $100 \%$ \\
\hline Average & 11.8 & $54 \%$ & $41 \%$ & $95 \%$ \\
\hline
\end{tabular}

If two firms share a supplier or distributor, then they are separated by one degree, according to the classic "small worlds" measure (Watts, 1999). Our analysis suggests that, because of extensive network sharing, the average degree of separation between firms in these two sectors is low, but this remains an open empirical question.

In summary, the largest firms in the two sectors are similar in that they have overlapping supplier networks but rarely transact directly with each other. The firms differ markedly, however, in terms of the products they choose to sell. The largest automotive firms rarely sold to other firms in their sector, while the largest electronics firms commonly did so. In the next 
section, we discuss the implications of these findings.

\section{Discussion}

Our cross-sector analysis sheds light on prior theories in economic sociology and management, and it complements prior empirical work on the structure of alliance networks. It also establishes a direct correspondence between the practices of individual firms at the micro level and measurable properties of a transaction network at the macro level.

In economic sociology, H. White (2002a) argued that production markets are socially constructed from networks of firms for whom the relationships "upstream" and "downstream" are fundamental. Nakano and D. White (2007) went on to hypothesize that transaction networks in production markets would exhibit strict hierarchy; i.e., the firms would be strictly ordered from upstream to downstream. To test that hypothesis, we used a new metric to measure hierarchy of two transaction networks in Japan in 1993. We were able to show that strict hierarchy might be characteristic of some but not all transaction networks, thus refuting the strong form of the hypothesis.

In management, Jacobides and Winter (2005) argued that the vertical scope of firms is co-determined by heterogeneous capabilities and endogenous transaction costs. Baldwin (2008) further argued that transaction costs are lowest at the "thin crossing points" of an underlying network of production and knowledge transfers, and that such boundary points are partially endogenous. This paper has developed a methodology for observing and comparing transaction networks, which are superimposed on more complex networks of goods and knowledge flows in the economy. Applying our methodology to the Japanese automotive and electronics sectors in 1993, we found that both sectors contained densely connected transactions in which exclusive relationships (captive suppliers or customers) were not characteristic. This is different from the pattern of vertical integration observed by Chandler (1990) in the United States in the late $19^{\text {th }}$ century, where large firms created independent supply chains and distribution channels.

We were also able to identify differences between the sectors. In general, automotive firms almost never sold to firms from whom they purchased goods directly or indirectly. Hence this sector displayed nearly absolute hierarchy with almost no transaction cycles (see Table 4 and Figure 2). In contrast, in the electronics sector, the largest firms concurrently bought and sold 
components in transactions with other firms within the sector, in addition to their selling systems to end-users. Indeed, nine of the 10 largest firms were part of a single strongly connected component (see Figure 2); i.e., they both purchased and sold goods to each another, although through indirect relationships. The largest firms were also critical to the architecture of the network: When we removed them, the number of cycles dropped significantly and the transaction network became substantially more hierarchical (see Table 3).

Our analysis complements prior work on alliance networks, especially the cross-industry comparative analysis of Rosenkopf and Schilling (2007). In their analysis, Rosenkopf and Schilling found that the automotive, computer, and communication equipment industries ${ }^{15}$ all had dense and non-separable alliance networks. Although we looked at data from a different country and time, we also found high density and non-separability (in the form of overlapping suppliers and distributors) in the transaction networks of these sectors. However, because alliance networks contain only non-directed links, hierarchy cannot be established in them. Understanding how alliance and transaction networks are related is an interesting avenue for future research. (Helper et al., 2000 provide a starting point for this line of work.)

To our knowledge, this paper is one of the first to demonstrate a connection between complex boundary decisions by individual firms and macro-level industry structure. It is well known that firms' decisions to integrate or specialize, when widely adopted, lead to vertically integrated or horizontally layered industry structures (see, for example, Baldwin and Clark, 2000; Jacobides, 2005; and Fixson and Park, 2008). However, studies at the firm level, starting with Harrigan (1985), have shown that the boundary and scope decisions of firms are often more complex than simply to integrate or specialize. In particular, firms often practice concurrent sourcing (tapered integration) or have two-way vertically permeable boundaries. We have seen that, in order for cycles to form in a transaction network, some firms must concurrently source and sell intermediate goods; i.e., they must have two-way vertically permeable boundaries. However, only a small number of firms need to adopt this practice to have a dramatic effect on the architecture of the transaction network.

What causes the difference in boundary choices of the largest firms in our two sectors? Unfortunately, our data do not allow us to answer that question. Nevertheless, as a prelude to

\footnotetext{
15 The computer and communications equipment industries in their data roughly correspond to the electronics sector in our data.
} 
further inquiry, we offer two possible explanations, one cultural and the other technological. We believe the cultural explanation cannot explain the differences we observe, because the cultural context of the two sectors is very similar. The technological explanation takes us further but still leaves important questions unanswered.

On first glance, one might look at the keiretsu business culture in Japan for a possible explanation of that country's transaction networks. A keiretsu is a group of companies with long-time interlocking business relationships and shareholdings (Sako, 1992; Nishiguchi, 1994; Paprzycki, 2005; Nagaoka et al., 2008). In fact, our data show that many of the direct suppliers of the 10 largest firms in the automotive sector are keiretsu members, as are many customers and "cycle partners" of the 10 largest firms in the electronic sector. But transaction cycles only arose widely in the electronics sector. Thus, the keiretsu business culture, which is present in both sectors, cannot by itself explain the differences in hierarchy.

From interviews with key managers in the automotive sector, we learned that virtually every component must be designed specifically for the system in which it will function (Luo, 2010). This was true in the automotive sector during the time of our data; and it remains true today. As a result, supplier-customer relations in this sector have generally taken the form of long-term relational contracts with high levels of interaction and joint problem-solving (Asanuma, 1989; Sako, 1992; Nishiguchi, 1994; Baldwin, 2008; Nagaoka et al., 2008). Inevitably, to get the various components to work together properly, suppliers and customers must share knowledge and, because of that, a big concern is that valuable knowledge may leak out to customers that are also competitors (Baldwin and Henkel, 2011; Alcácer and Zhao, 2012). At the same time, external sales of components do not generate significant economies of scale, because each component is specialized to a particular system. Taken together, the risk of knowledge spillovers to competitors and the lack of economies of scale reduce the incentives of vertically integrated automotive companies to sell internally manufactured components to other firms in their sector.

In the electronics sector, the situation is much different because the risks of knowledge spillovers are substantially lower and the potential economies of scale are higher. Here components are modular black boxes, whose internal structure can be concealed behind standardized interfaces (Whitney, 1996; Baldwin and Clark, 2000). Such components can be recombined in many different types of systems (e.g., computers, TVs, and mobile phones), and 
thus potential economies of scale are high. Indeed, if the component division of a vertically integrated electronics firm supplies only its in-house divisions, it may not be able to achieve minimum efficient scale. By selling components to external customers, component divisions can increase their production volumes and thus be cost-competitive with vertically specialized firms. (Note that, in our data, the component divisions of the largest firms never sold directly to other large firms. Whether their components indirectly found their way into the systems of competitors is an open question.)

But all that raises another question: In the presence of high levels of component modularity and innovation, why should firms in the electronics industry remain vertically integrated at all? Since the mid-1990s, the ratio of component sales to overall sales for the largest Japanese electronics firms has been stable and significant: in the range of $12 \%$ to $24 \%$ (Luo, 2010, pp.114-5). Vertical integration by the largest firms thus appears to be a stable feature of the industry's overall architecture. What explains it?

As indicated in the literature review, prior studies have shown that systems integrators need to maintain a broad spectrum of capabilities along the value chain and that firms that outsource components may ultimately lose control of critical component knowledge (Fine and Whitney, 1999; Brusoni et al., 2001; Davies, 2004; Ceci and Masini, 2011; Kapoor, 2011). In our interviews, managers in the electronics sector in Japan stated their belief that detailed knowledge of the technologies within key components was a source of competitive advantage in designing system-level products. Such knowledge, they maintained, was more readily obtained from in-house divisions than from external suppliers (Luo, 2010).

Overall, this knowledge-based explanation of vertical integration is in line with previous foundational work on knowledge-based sector specificities (Nelson and Winter, 1982; Pavitt, 1984; Malerba and Orsenigo, 1996; Patel and Pavitt, 1997; Malerba, 2002). The argument is that the features of a sector's technological base in conjunction with firms' scope decisions tend to shape the firms' innovation opportunities. Consistent with this view, the managers we interviewed asserted that the largest Japanese electronics firms have remained vertically integrated to maintain access to component-level knowledge, which in turn has benefited their system-level innovation opportunities. 


\section{Conclusion}

This paper contributes to the literatures on industry architecture and the sociology of markets by investigating the transaction networks of two large sectors in Japan at a single point in time. In this investigation, our primary lens was "hierarchy," defined as the degree to which transactions in the network flow in one direction, from "upstream" to "downstream." We showed that the Japanese electronics sector exhibits a much lower degree of hierarchy than the automotive sector because it contains numerous inter-firm transaction cycles. Furthermore, we traced the observed differences in hierarchy to differences in the largest firms' practices with respect to two-way vertically permeable boundaries and component sales within the sector.

Like all studies, this one has certain limitations. First, because of the difficulty of obtaining good transactions data, we were able to analyze only two sectors in the same country in the same year (1993). Data for other sectors with different technological bases, cultures (e.g. American, European, or Chinese), and in different stages of industry evolution would have provided a better test of our empirical results and theoretical reasoning. It is difficult, however, to collect sector-wide data on transactions because many firms are unwilling to share information on their suppliers and customers. In time, we hope that new data sources will become available.

Because of a lack of data, this study could not address questions involving sector dynamics. The network architectures we observed might have been transient, non-equilibrium patterns. This is more likely to be a problem in the electronics sector, for which we had only a snapshot year (1993), than in the automotive sector, for which we had three observations spanning 18 years (1983-2001).

This paper opens up several avenues of potential future research. First, there are opportunities to extend the methodology. To gain a better understanding of transaction networks, it is necessary to look beyond simple cycle counts to cycle location, the presence of strongly connected components, and the degrees of separation between competing firms. Recent work by MacCormack et al. (2010) investigates some of these methodological questions.

Second, there is an opportunity to integrate transaction network analysis with ongoing empirical work on sectors. Specifically, as supply networks become more extensive and far-flung, there is a growing need for transaction network analysis to inform public policy. As one example, in 2009, General Motors and Chrysler received government financial support based largely on the claim that their failure would have imposed great cost on their domestic supply 
chains. But no information was publicly disclosed regarding the identities of their direct or indirect suppliers or the extent of their supply networks. In this case, transaction network analysis could have provided useful information to inform public policy. Other potential applications of transaction network analysis include the assessment of credit risk, product safety, and the security of supply networks for defense. Finally, investigating the relationships between transaction networks and alliance networks offers an opportunity to develop a better understanding of the flows of goods and knowledge within a sector and the ways in which those flows are related.

We also see an opportunity to use transaction network data to shed light on firm strategies. Such work must bridge the firm and sector levels of analysis. One example of that is with respect to vertical integration. Kapoor (2011) has hypothesized that, as industries become more vertically specialized, new opportunities emerge for the remaining vertically integrated firms to focus on system-level innovations. This hypothesis is consistent with our explanation, gleaned from interviews, as to why large electronics firms in Japan have remained vertically integrated. At the same time, our findings on two-way vertically permeable boundaries may explain how vertically integrated firms remain competitive in sectors with high rates of component innovation. Another example is with respect to the different roles that firms can play. In the electronics sector, we found that, even though nine of the 10 largest firms were part of a single cyclic group (strongly connected component), they almost never directly bought or sold to each other. Hence the sector must have contained firms that served as intermediaries between the largest firms. Identifying such firms and exploring their roles and strategies is an open avenue for future work that would combine network and firm-level data.

In conclusion, we hope this paper will be seen as an invitation for further exploration of transaction networks and their architecture in a wide range of settings. 


\section{Acknowledgments}

We thank Michael Jacobides, Joel Moses, Oliver de Weck, Joel Sussman, Daniel Roos, Margaret Dalziel, William Mitchell, Lee Branstetter, Susan Helper, Venkat Kuppuswamy, John Paul MacDuffie, and Rahul Kapoor, whose insights helped to refine this research, as well as seminar participants at Carnegie Mellon University, the University of Tokyo, Yokohama National University, the University of Cambridge, the Chinese University of Hong Kong, University of Ottawa, New York University, Massachusetts Institute of Technology, and the Academy of Management professional development workshop on Innovation, Firm, and Ecosystem. The authors also thank the International Motor Vehicle Program, the MIT-Portugal Program at MIT, and Harvard Business School for financial support. We also thank Takahiro Fujimoto, Daniel Heller, Masanori Yasumoto, and other researchers at the Manufacturing Management Research Center at the University of Tokyo for generous support and help with the field work and data collection in Japan, and the executives and managers of the firms we visited and interviewed for their time, patience, valuable input, and the spirit of knowledge sharing. We thank Alan MacCormack and John Rusnak for helping us to analyze the DSMs for transaction networks and Alden Hayashi for editing the manuscript. And we are especially grateful to three anonymous referees for detailed comments and criticism that greatly improved the article. The authors alone are responsible for any errors and oversights. 


\section{References}

Adner, R. and R. Kapoor (2010), 'Value creation in innovation ecosystems: how the structure of technological interdependence affects firm performance in new technology generations,' Strategic Management Journal, 31, 306-333.

Ahl, V. and T. F. H. Allen (1996), Hierarchy Theory: A Vision, Vocabulary and Epistemology. Columbia University Press: New York.

Alcácer, Juan and Minyuan Zhao (2012), 'Local R\&D strategies and multilocation firms: The role of internal linkages,' Management Science (forthcoming).

Aoki, M. (1988) Information, Incentives, and Bargaining in the Japanese Economy, Cambridge University Press: Cambridge, UK.

Asanuma, B. (1989), 'Manufacturer-supplier relationships in Japan and the concept of relation-specific skill,' Journal of the Japanese and International Economies, 3(1): 1-30.

Baldwin, C. Y. (2008), 'Where do transactions come from? Modularity, transactions, and the boundaries of firms,' Industrial and Corporate Change, 17(1), 155-195.

Baldwin, C. Y. and K. B. Clark (2000), Design Rules, Volume 1: The Power of Modularity. MIT Press: Cambridge, MA.

Baldwin, C. Y. and J. Henkel (2011), 'The impact of modularity on intellectual property and value appropriation,' Harvard Business School Working Paper \#12-040 (December).

Borgatti, S. P. (2002), NetDraw: Graph Visualization Software. Analytic Technologies: Lexington, MA.

Brusoni, S. and A. Prencipe (2001), 'Unpacking the black box of modularity: Technologies, products and organizations,' Industrial and Corporate Change, 10(1), 179-205.

Brusoni, S., A. Prencipe and K. Pavitt (2001), 'Knowledge specialization, organizational coupling, and the boundaries of the firm: Why do firms know more than they make?' Administrative Science Quarterly, 46(4), 597-621.

Cacciatori, E. and M. G. Jacobides (2005), 'The dynamic limits of specialization: Vertical integration reconsidered,' Organization Studies, 26(12): 1851-1883.

Castellacci, F. (2007), 'Technological regimes and sectoral differences in productivity growth,' Industrial and Corporate Change, 16(6), 1105-1145

Ceci, F. and A. Masini (2011), 'Balancing specialized and generic capabilities in the provision of integrated solutions,' Industrial and Corporate Change, 20(1), 91-131.

Chandler, A. D. (1990), Scale and Scope: The Dynamics of Industrial Capitalism. Belknap Press of Harvard University Press: Cambridge, MA.

Christensen, C. M. and R. S. Rosenbloom (1995), 'Explaining the attacker's advantage: technological paradigms, organizational dynamics, and the value network,' Research Policy, 24, 233-257. 
THE ARCHITECTURE OF TRANSACTION NETWORKS

Christensen, C. M., Verlinden, M. and G. Westerman (2002), 'Disruption, disintegration and the dissipation of differentiability,' Industrial and Corporate Change, 11(5): 955-993.

Coase, R. H. (1937), 'The nature of the firm,' Economica, 4(4), 386-405.

Commons, J. R. (1934), Institutional Economics: Its Place in Political Economy. Macmillan: New York.

Dalziel, M. (2007), 'A systems-based approach to industry classification,' Research Policy, 36, 1559-1574.

Dosi, G. (1988), 'Sources, procedures, and microeconomic effects of innovation,' Journal of Economic Literature, 26(3), 1120-1171.

Davies, A. (2004), 'Moving base into high-value integrated solutions: a value stream approach,' Industrial and Corporate Change, 13(5), 727-756.

Eppinger, S. D., D. E. Whitney, R. P. Smith and D. A. Gebala (1994), 'A model-based method for organizing tasks in product development,' Research in Engineering Design, 6, 1-13.

Fine, C. H. (1998), Clockspeed: Winning Industry Control in the Age of Temporary Advantage. Perseus Press: Reading, MA.

Fine, C. H. and D. E. Whitney (1999), 'Is the make-buy decision a core competence?' in Muffatto, M. and K. Pawar (eds.), Logistics in the Information Age. Servizi Grafici Editoriali: Padova, Italy, pp. 31-63.

Fixson, S. K. and J-K Park (2008), 'The power of integrality: Linkages between product architecture, innovation, and industry structure,' Research Policy, 37(8), 1296-1316.

Gulati, R. (1995), 'Does familiarity breed trust? The implications of repeated ties for contractual choice in alliances,' Academy of Management Journal, 38(1), 85-112.

Gulati, R. (1998), 'Alliances and networks,' Strategic Management Journal, 19(4), 293-318.

Harrigan, K. R. (1985), 'Vertical integration and corporate strategy,' Academy of Management Journal, 28(2), 397-425.

Helfat, C. E. and M. Campo-Rembado (2010), 'Integrative capabilities, vertical integration, and innovation over successive technology life cycles,' Working Paper, Tuck School of Business at Dartmouth.

Helper, S., J. P. MacDuffie and C. Sabel (2000), 'Pragmatic collaborations: advancing knowledge while controlling opportunism,' Industrial and Corporate Change, 9(3), 443 488 .

Iansiti, M. and R. Levien (2004), The Keystone Advantage: What the New Dynamics of Business Ecosystems Mean for Strategy, Innovation, and Sustainability. Harvard Business School Press: Boston.

Jacobides, M. G. (2005), 'Industry change through vertical disintegration: how and why markets emerged in mortgage banking,' Academy of Management Journal, 48(3), 465-498.

Jacobides, M. G. and S. Billinger (2006), 'Designing the boundaries of the firm: from "make, buy, or ally" to the dynamic benefits of vertical architecture,' Organization Science, 17(2), 249-261. 
Jacobides, M. G., T. Knudsen and M. Augier (2006), 'Benefiting from innovation: value creation, value appropriation and the role of industry architectures,' Research Policy, 35, 1200-1221.

Jacobides, M.G. and S.G. Winter (2005), 'The co-evolution of capability and transaction costs: explaining the institutional structure of production,' Strategic Management Journal, (26)5, 395-413.

Kapoor, R. (2011), 'Negotiating the winds of disintegration as industries evolve: Assessing incumbent response to structural changes in the semiconductor industry,' Working Paper, The Wharton School, University of Pennsylvania, May 24, 2011.

Lafontaine, F. and Slade, M. (2007), 'Vertical integration and firm boundaries: The evidence,' Journal of Economic Literature, 45(3), 629-685.

Langlois, R. N. and P. L. Robertson (1992), 'Networks and innovation in a modular system: lessons from the microcomputer and stereo component industries,' Research Policy, 21, 297-313.

Luo, J. (2010), Hierarchy in Industry Architecture: Transaction Strategy under Technological Constraints, Doctoral Dissertation, Massachusetts Institute of Technology.

Luo, J. and C. L. Magee (2011), 'Detecting evolving patterns of self-organizing networks by flow hierarchy measurement,' Complexity, 16(6), 53-61.

MacCormack, A., J. Rusnak and C. Y. Baldwin (2006), 'Exploring the structure of complex software designs: an empirical study of open source and proprietary code,' Management Science, 52(7), 1015-1030.

MacCormack, A., J. Rusnak and C.Y. Baldwin, (2010) 'The architecture of complex systems: Do core-periphery structures dominate,' Harvard Business School Working Paper, \#10-059.

Malerba, F. (2002), 'Sectoral systems of innovation and production,' Research Policy, 31, 247-264.

Malerba, F. and L. Orsenigo (1993), 'Technological regimes and firm behavior,' Industrial and Corporate Change, 2(1), 45-71.

Malerba, F. and L. Orsenigo (1996), 'Schumpeterian patterns of innovation are technology-specific,' Research Policy, 25, 451-478.

Malerba, F. and L. Orsenigo (1997), 'Technological regimes and sectoral patterns of innovative activities,' Industrial and Corporate Change, 6(1), 83-118.

Nagaoka, S., A. Takeishi and Y. Norob (2008), 'Determinants of firm boundaries: empirical analysis of the Japanese auto industry from 1984 to 2002,' Journal of the Japanese and International Economies, 22(2), 187-206.

Nakano, T. and D. R. White (2007), 'Network structures in industrial pricing: the effect of emergent roles in Tokyo supplier-chain hierarchies,' Structure and Dynamics, 2 (3), 1.

Nelson, R. and S. Winter (1982), An Evolutionary Theory of Economic Change. The Belknap Press of Harvard University Press: Cambridge, MA.

Nishiguchi, T. (1994), Strategic Industrial Sourcing: The Japanese Advantage. Oxford University Press: USA. 
Paprzycki, R. (2005), Interfirm Networks in the Japanese Electronics Industry. RoutledgeCurzon: London and New York.

Parmigiani, A. (2007), 'Why do firms both make and buy? An investigation of concurrent sourcing,' Strategic Management Journal, 28, 285-311.

Parmigiani, A. and W. Mitchell (2009), 'Complementarity, capabilities, and the boundary of the firm: The impact of within-firm and interfirm expertise on concurrent sourcing of complementary components,' Strategic Management Journal, 30, 1065-1091.

Patel, P. and K. Pavitt (1997), 'The technological competencies of the world's largest firms: complex and path-dependent, but not much variety,' Research Policy, 26, 141-156.

Pavitt, K. (1984), 'Sectoral patterns of technical change: Towards a taxonomy and a theory,' Research Policy, 13, 343-373.

Powell, W. W. (1990), 'Neither market nor hierarchy: Network forms of organization,' Research in Organizational Behavior, 12, 295-336.

Rosenkopf, L. and M. A. Schilling (2007), 'Comparing alliance network structure across industries: observations and explanations,' Strategic Entrepreneurship Journal, 1, 191-209.

Sako, M. (1992), Prices, Quality, and Trust: Inter-Firm Relations in Britain and Japan. Cambridge University Press: Cambridge, UK.

Schilling, M. A. and C. C. Phelps (2007), 'Interfirm collaboration networks: The impact of large-scale network structure on firm innovation,' Management Science, 53(7): 1113-1126.

Simon, H. A. (1962), 'The architecture of complexity,' Proceedings of the American Philosophical Society, 106, 467-82.

Sorenson, O. and T. E. Stuart (2001), 'Syndication networks and the spatial distribution of venture capital investments,' American Journal of Sociology, 106(6), 1546-1588.

Sosa, M., Eppinger, S. and C. Rowles (2004), 'The misalignment of product architecture and organizational structure in complex product development,' Management Science, 50(12), 1674-1689.

Strojwas, M. (2005), An Empirical Study of Vertical Integration in the Semiconductor Industry, Doctoral Dissertation, Harvard University.

Sturgeon, T. J. (2002), 'Modular production networks: a new American model of industrial organization,' Industrial and Corporate Change, 11(3), 451-496.

Wasserman, S. and K. Faust (1994), Social Network Analysis: Methods and Applications. Cambridge University Press: Cambridge; New York.

Watts, Duncan J. (1999), 'Networks, dynamics, and the small-world phenomenon,' American Journal of Sociology, 105(2), 493-527.

Williamson, O. E (1975), Markets and Hierarchy. Free Press: New York.

Williamson, O. E. (1985), The Economic Institutions of Capitalism: Firms, Markets, Relational Contracting. Free Press: New York.

White, H. C. (2002a), Markets from Networks: Socioeconomic Models of Production. Princeton University Press: Princeton, NJ. 
THE ARCHITECTURE OF TRANSACTION NETWORKS

White, H. C. (2002b), 'Businesses mobilize production through markets: parametric modeling of path-dependent outcomes in oriented network flows,' Complexity, 8(1), 87-95.

Whitney, D. E. (1996), 'Why mechanical design cannot be like VLSI design,' Research in Engineering Design, 8(3), 125-138. 